\title{
Role of interleukin-18 and plasma B-type natriuretic peptide in predicting requirement of kidney replacement therapy and/or mortality in individuals with acute heart disorders
}

\author{
Aida Hamzić-Mehmedbašić ${ }^{1,2}$, Damir Rebić ${ }^{1}$, Amina Valjevac ${ }^{3}$, Hajrunisa Čubro ${ }^{4}$, Azra Durak \\ Nalbantić ${ }^{5}$, Vedad Herenda ${ }^{1,2}$, Aida Kulo Ćesić \\ ${ }^{1}$ Nephrology Clinic, Clinical Center University of Sarajevo, Bolnička 25, 71000, Sarajevo, Bosnia and Herzegovina \\ ${ }^{2}$ Sarajevo Medical School, University Sarajevo School of Science and Technology, Hrasnička cesta 3a, 71000, Sarajevo, Bosnia and \\ Herzegovina \\ ${ }^{3}$ Department of Physiology, Faculty of Medicine, University of Sarajevo, Čekaluša 90, 71000, Sarajevo, Bosnia and Herzegovina \\ ${ }^{4}$ Department of Obstetrics and Gynecology, University of Louisville, 550 S Jackson St, Louisville, KY 40202, USA \\ ${ }^{5}$ Heart Disease Clinic, Clinical Center University of Sarajevo, Bolnička 25, 71000, Sarajevo, Bosnia and Herzegovina \\ ${ }^{6}$ Department of Pharmacology, Faculty of Medicine, University of Sarajevo, Čekaluša 90, 71000, Sarajevo, Bosnia and Herzegovina
}

\section{A R T I C L E I N F O}

\section{Article Type:}

Original

\section{Article History:}

Received: 7 May 2018

Accepted: 9 August 2018

Published online: 14 September 2019

\section{Keywords:}

Acute heart disorders

Interleukin-18

B-type natriuretic peptide

Dialysis

Mortality

\begin{abstract}
A B S T R A C T
Introduction: Although many predictive tools have already been developed, efforts are still proceeding to identify a reliable biomarker to predict the prognosis of the patients with acute heart disorders.

Objectives: The aim was to evaluate the role of renal injury biomarkers (serum cystatin C, serum and urine interleukin-18, IL-18) and heart failure biomarkers (plasma B-type natriuretic peptide, BNP) in the prediction of the postdischarge requirement of renal replacement therapy (RRT) and/or 6-month mortality in patients with acute heart disorders.

Patients and Methods: In patients diagnosed with acute heart disorders (acute heart failure $[\mathrm{AHF}]$ and/or acute coronary syndrome [ACS]) and admitted to the intensive care units, baseline clinical parameters, renal and cardiac biomarkers were determined. Patients were followed up for 6 months. The composite outcome was the postdischarge requirement of RRT and/or 6-month mortality.

Results: Of 120 patients, 5.8\% continued RRT after discharge. The 6-month mortality was $20 \%$. Cox logistic regression analysis showed that urine IL-18 $(P=0.021)$, plasma BNP $(P=0.046)$, Acute Physiology and Chronic Health Evaluation (APACHE) II score $(P=0.002)$, and left ventricular diastolic dysfunction $(P=0.045)$ were independent predictors of the postdischarge requirement of RRT and/or 6-month mortality. For predicting RRT and/or 6-month mortality, using urine IL-18 cutoff value of $29.1 \mathrm{pg} / \mathrm{mL}$ showed $66.7 \%$ sensitivity and $67.7 \%$ specificity (area under the curve, AUC 0.70, $P=0.003$ ), while using plasma BNP cutoff value of $881.6 \mathrm{pg} / \mathrm{mL}$ showed $66.7 \%$ sensitivity and $70.8 \%$ specificity (AUC $0.76, P<0.001$ ).

Conclusion: Urine IL-18 and plasma BNP are independently predictive for the postdischarge requirement of RRT and/or 6-month mortality in patients with acute heart disorders.
\end{abstract}

Implication for health policy/practice/research/medical education:

Prognostic value of renal and cardiac biomarkers is ascertained in recognizing high risk patients with acute heart disorders. Thoughtful use of cardiorenal biomarkers allows not only diagnostic assessment of acute cardiac patients with potential worsening of renal function but also monitoring of renal disease progression in this patient population. As these patients with acute heart disorders may need more strategic and tailored treatment in order to prevent future risk of an adverse event, novel cardiac and renal biomarkers can be helpful on this matter.

Please cite this paper as: Hamzić-Mehmedbašić A, Rebić D, Valjevac A, Čubro H, Durak Nalbantić A, Herenda V, et al. Role of interleukin-18 and plasma B-type natriuretic peptide in predicting requirement of kidney replacement therapy and/or mortality in individuals with acute heart disorders. J Renal Inj Prev. 2019;8(4):292-300. DOI: 10.15171/jrip.2019.54. 


\section{Introduction}

Acute heart failure (AHF) and acute coronary syndrome (ACS), especially myocardial infarction are serious lifethreating cardiovascular diseases. Renal impairment is common in these patients since the kidney represents an important part of fluid and sodium transfer system in the human body $(1,2)$. Chronic kidney disease (CKD) and the lethal outcome is more likely to be found in patients with heart failure (HF) in comparison with individuals without HF (3). Worsening of renal function is associated with an increased risk of in-hospital death, HF and cardiogenic shock in patients with ACS (4). According to a recent metaanalysis, acute kidney injury (AKI) occurred in 35.3\% of AHF patients, $22.1 \%$ of cardiac surgery patients and $12.7 \%$ of ACS patients (5). New onset AKI in acute cardiac patients was linked with 5-times increased mortality risk. Furthermore, if acute cardiac patients diagnosed with AKI underwent renal replacement therapy (RRT), the risk of mortality was doubling (5).

Assessment of renal and cardiac biomarkers offers prognostic information in different fields of medicine such as cardiac surgery, intensive coronary units (ICUs), and transplantation (6-8). Nevertheless, prediction of adverse future events in patients with acute heart disorders remains challenging. Several candidates among biologic markers with promising prognostic potential in acute cardiac events have emerged in recent years (9). However, to our best knowledge, there is only one investigation that assessed the ability of biomarkers to predict overall and renal survival in patients admitted to ICU for the reason of acute cardiac events. However, postdischarge need for dialysis was not observed in this study (10).

\section{Objectives}

This investigation aimed to examine the role of renal injury biomarkers (serum cystatin $\mathrm{C}$, serum and urine interleukin-18, IL-18) and HF biomarkers (plasma B-type natriuretic peptide, BNP) in the prediction of the postdischarge requirement of RRT and/or 6-month mortality in patients with acute heart disorders admitted to ICUs.

\section{Patients and methods}

\section{Design and population of the study}

The study was designed as a prospective and observational study. It was performed at the ICUs of the Heart Disease Clinic and Nephrology Clinic of the Clinical Center University of Sarajevo (CCUS). All consecutive patients admitted to ICUs with the diagnosis of AHF and/ or ACS during the 7-months period were eligible for enrollment. The inclusion criteria were patients older than 18 years diagnosed with AHF and/or ACS with the length of hospital stay longer than 48 hours. The exclusion criteria were end-stage kidney disease, renal transplant, preexisting dialysis before ICUs admission, or missing admission data. All subjects signed informed consent.

\section{Laboratory and Biomarker Measurements}

Measurements of serum creatinine were obtained at admission, 48 hours and 7 days after admission, as well as at discharge. The leukocytes, hemoglobin, sodium, blood urea nitrogen (BUN), albumin, C-reactive protein (CRP), uric acid, troponin I were measured at admission. 24hour urine output was measured during hospitalization. Proteinuria, albuminuria, and biomarker measurements were obtained in the first 24-hours of hospital stay. Measurements of cystatin C in serum, as well as IL-18 in serum and urine, were performed by ELISA (R\&D Systems). Plasma BNP level was measured by microparticle immunoassay method (Abbott Laboratories).

\section{Definitions}

AHF was defined using the European Society of Cardiology Criteria (11). The diagnosis of ACS encompassed unstable angina, non-ST-segment-elevation myocardial infarction, and ST-segment-elevation myocardial infarction. The acute myocardial infarction was defined using the consensus of the recommendations of international experts in the field of cardiology (12).

The Chronic Kidney Disease Epidemiology Collaboration equation was used to calculate estimated glomerular filtration rate (eGFR) (13). CKD was recorded in individuals with documented eGFR $<60$ $\mathrm{mL} / \mathrm{min}$ and a history of CKD that lasted at least three months. Antecedents of hypertension, diabetes mellitus, and anemia were recorded for all patients. Anemia was defined as a plasma hemoglobin concentration $<135 \mathrm{~g} / \mathrm{L}$ in men $(<132 \mathrm{~g} / \mathrm{L}$ in men over the age of 70$)$ or $<120$ $\mathrm{g} / \mathrm{L}$ in women. Charlson comorbidity index (CCI) score was used to assess the presence of comorbid conditions (14). The Acute Physiology and Chronic Health Evaluation (APACHE) II score was used to assess the severity of illness (15). Transthoracic echocardiographic measurements were performed according to the available published guidelines. Internal dimensions were obtained with two-dimensional echocardiography guided M-mode approach (16). Left ventricular systolic function was assessed by calculating ejection fraction (EF). EF of $<50 \%$ was suggestive of abnormal left ventricular systolic function, and $\mathrm{EF}<35 \%$ was considered as severe systolic dysfunction. Using the transmitral flow signal, peak early diastolic velocity (E), peak late diastolic velocity (A), and the E/A ratio were measured. An E/A ratio $<1$ was suggestive of abnormal left ventricular diastolic function. Further categorization of abnormal left ventricular diastolic function encompassed abnormal relaxation, pseudo-normalization and restrictive filling (17).

\section{Outcome definitions}

Because the majority of patients in ICUs received diuretics, 
AKI was defined according to Acute Kidney Injury Network (AKIN) criteria based on serum creatinine values. AKI was diagnosed within the first 48 hours of hospitalization in patients with a detected increase in serum creatinine of $0.3 \mathrm{mg} / \mathrm{dL}(\geq 26.4 \mu \mathrm{mol} / \mathrm{L})$ or more, or in patients with the percentage increase in serum creatinine of $50 \%$ (1.5-fold from baseline) or more (18).

In-hospital mortality was recorded. Patients treated with acute RRT during hospital stay were recorded. Hospital survivors were followed up six months after discharge. The composite outcome was the post-discharge need for RRT and/or 6-month mortality. According to the composite outcome, we created two groups of patients: renal and/or overall nonsurvivors and renal and/or overall survivors. Patients who continued RRT and/or died at any point during 6-month follow up were considered to be renal and/or overall nonsurvivors, while patients who were not treated with RRT and/or survived during 6-month follow up were considered to be renal and/or overall survivors.

\section{Ethical issues}

The research was conducted according to the criteria set by the Declaration of Helsinki. It was approved by the Medical Ethics Committee of the Clinical Center University of Sarajevo (0207-27144).

\section{Statistical analysis}

Statistical analysis were performed with SPSS software version 17.0 (SPSS, Inc., Chicago, Illinois). Continuous variables with normal distribution were expressed as mean \pm standard deviation, and continuous variables whose distribution was not normal were expressed as median (interquartile range). Categorical variables were expressed as a number (percentage). To compare continuous variables with normal distribution, a twosample $t$ test was used, and for continuous variables whose distribution was not normal, a Mann-Whitney U test was used. To compare categorical variables, the chi-square or Fisher's exact test was used. The independent prognostic values of renal and cardiac biomarkers, echocardiographic parameters as well as illness severity and comorbidity scores were assessed by univariate Cox proportional hazards regression analysis, followed by multivariate Cox proportional hazards regression analysis which included variables that were associated with outcomes in univariate analysis. Kaplan-Meier analysis was performed when patients were stratified based on quartiles of urine IL-18 levels and based on median plasma BNP; the differences between survival and event-free rate curves were analyzed by log-rank test. The sensitivity and specificity of urine IL-18 and plasma BNP values for predicting postdischarge RRT and/or 6-month mortality were determined, and receiver operating characteristic (ROC) curves were constructed by plotting sensitivity against (1- specificity). The area under the curves (AUCs) were calculated and analyzed by one-tailed test. Cutoff points were calculated by acquiring the best Youden index. All tests of $P<0.05$ was respected to be significant.

\section{Results}

Of 131 screened individuals, 11 died during hospitalization and 120 patients were followed up 6 months after discharge.

Baseline characteristics, values of renal and cardiac markers as well as outcomes of patients were presented in Table 1 . The average age of the patients included in this report was $69.3 \pm 11.8$ years, and $65.6 \%$ of the patients were men. History of CKD was found in $35.9 \%$ of individuals, history of diabetes mellitus in $42.0 \%$ of patients, and hypertension in $68.7 \%$ of patients. The mean EF was $40.0 \pm 10.8$ with systolic dysfunction $(\mathrm{EF}<50 \%)$ in $66.4 \%$, and diastolic dysfunction $(\mathrm{E} / \mathrm{A}<1)$ in $72.5 \%$ of patients. AKI was diagnosed in $46.8 \%$ of patients. The portion of patients who underwent RRT during hospitalization was 9.2\% (12/131), and 5.8\% (7/120) patients continued RRT after discharge. The in-hospital and 6-month mortality rate were $8.5 \%$ and $20 \%$, respectively.

Concentrations of BUN $(P<0.001)$, serum creatinine $(P<0.001)$, as well as serum cystatin $\mathrm{C}(P<0.001)$, serum IL-18 $(P=0.001)$, urine IL-18 $(P<0.001)$, and plasma BNP $(P<0.001)$ were significantly higher in renal and/ or overall nonsurvivors when compared to renal and/ or overall survivors. APACHE II score $(P<.001)$ and CCI score $(P<0.001)$ were significantly higher, while EF $(P=0.032)$ was significantly lower in renal and/ or overall nonsurvivors in comparison to renal and/ or overall survivors. Furthermore, the incidences of CKD $(P<0.001)$, and diastolic dysfunction (abnormal relaxation $)(P=0.002)$ were significantly higher in renal and/or overall non-survivors (Table 2).

Univariate Cox analysis identified older age, higher concentration of BUN, serum creatinine, albuminuria, proteinuria, $\mathrm{CRP}$, uric acid, serum cystatin $\mathrm{C}$, serum and urine IL-18, plasma BNP, higher APACHE II and CCI score, severe systolic dysfunction, diastolic dysfunction (abnormal relaxation), previous history of CKD, new onset $\mathrm{AKI}$, as well as lower values of mean arterial pressure, EF, eGFR, and lower urine output to be associated with postdischarge RRT and/or 6-month mortality (Table 3). In multivariate Cox analysis urine IL-18, plasma BNP, APACHE II score and diastolic dysfunction (abnormal relaxation) were independent predictors for postdischarge RRT and/or 6-month mortality in patients with acute heart disorders (Table 3).

The ROC analysis confirmed that urine IL-18 and plasma BNP were the best predictors for postdischarge RRT and/or 6-month mortality in patients admitted for acute heart disorders. The ROC curve for urine IL-18 produced an AUC of $0.7(P=0.003)$ with a sensitivity of $66.7 \%$ and specificity of $67.7 \%$ for the cutoff point of $29.1 \mathrm{pg} / \mathrm{mL}$ (Figure 1). Figure 2 shows Kaplan-Meier curves displaying the association among concentrations 
Table 1. The baseline characteristics, values of renal and cardiac biomarkers and outcomes of patients with acute heart disorders

\begin{tabular}{|c|c|}
\hline Patients characteristics & \\
\hline Age (y) & $69.3 \pm 11.8$ \\
\hline Gender, Male, No. (\%) & $86(65.6 \%)$ \\
\hline $\mathrm{Hgb}(\mathrm{g} / \mathrm{L})$ & $135.3 \pm 22.1$ \\
\hline BUN (mmol/L) & $8.2(6.4-11.5)$ \\
\hline Serum creatinine ( $\mu \mathrm{mol} / \mathrm{L})$ & $92.0(75.0-118.0)$ \\
\hline eGFR $\left(\mathrm{mL} / \mathrm{min} / 1.73 \mathrm{~m}^{2}\right)$ & $77.12 \pm 24.6$ \\
\hline Albuminuria (mg/24h) & $33.2(20.3-95.4)$ \\
\hline Troponin I ( $\mu \mathrm{g} / \mathrm{L})$ & $0.09(0.036-1.21)$ \\
\hline CRP (mg/L) & $12.6(4.5-33.6)$ \\
\hline Uric acid ( $\mu \mathrm{mol} / \mathrm{L})$ & $424.0(329.0-579.0)$ \\
\hline APACHE II score & $11.6 \pm 5.0$ \\
\hline $\mathrm{CCl}$ score & $6.22 \pm 2.7$ \\
\hline \multicolumn{2}{|l|}{ Comorbidities } \\
\hline CKD, No. (\%) & 47 (35.9\%) \\
\hline Diabetes mellitus, No. (\%) & $55(42.0 \%)$ \\
\hline Hypertension, No. (\%) & $90(68.7 \%)$ \\
\hline Anemia, No. (\%) & $44(33.6 \%)$ \\
\hline \multicolumn{2}{|l|}{ Etiology of admission } \\
\hline AHF, No. (\%) & $87(66.4 \%)$ \\
\hline ACS, No. (\%) & $25(19.0 \%)$ \\
\hline AHF and ACS, No. (\%) & $19(14.6 \%)$ \\
\hline \multicolumn{2}{|l|}{ Clinical presentation } \\
\hline Mean arterial pressure (mm Hg) & $102.1 \pm 21.9$ \\
\hline Heart rate $(\mathrm{bpm})$ & $102.5 \pm 28.3$ \\
\hline Atrial fibrillation, No. (\%) & $55(42.0 \%)$ \\
\hline Sinus tachycardia, No. (\%) & $24(18.3 \%)$ \\
\hline Urine output <400 ml, No. (\%) & $24(18.3 \%)$ \\
\hline \multicolumn{2}{|l|}{ Echocardiographic parameters } \\
\hline$E F<50 \%$, No. (\%) & $87(66.4 \%)$ \\
\hline$E F<35 \%$, No. (\%) & $42(32.1 \%)$ \\
\hline LVMI $\left(\mathrm{g} / \mathrm{m}^{2}\right)$ & $137.5 \pm 32.5$ \\
\hline LVH & $101(77.1 \%)$ \\
\hline E/A <1, No. (\%) & $95(72.5 \%)$ \\
\hline$E / A<0.8$, No. (\%) & 45 (34.6\%) \\
\hline \multicolumn{2}{|l|}{ Biomarkers } \\
\hline Serum cystatin C (mg/L) & $1.28(1.01-1.86)$ \\
\hline Serum IL-18 (pg/mL) & $131.48(35.62-293.6)$ \\
\hline Urine IL-18 (pg/mL) & $16.39(0.00-139.91)$ \\
\hline Plasma BNP (pg/mL) & $663.4(254.4-1486.8)$ \\
\hline \multicolumn{2}{|l|}{ Outcomes } \\
\hline Incident AKI & $56(46.8 \%)$ \\
\hline Overall RRT & $12(9.2 \%)$ \\
\hline RRT after discharge & $7(5.8 \%)$ \\
\hline In-hospital mortality & $11(8.5 \%)$ \\
\hline 6-month mortality & $24(20 \%)$ \\
\hline
\end{tabular}

Data are presented as number (percent) or mean \pm standard deviation, or median (interquartile range).

No., number; Hgb, hemoglobin; BUN, blood urea nitrogen; eGFR, estimated glomerular filtration rate; CRP, C-reactive protein; APACHE, Acute Physiology and Chronic Health Evaluation; $\mathrm{CCl}$, Charlson comorbidity index; CKD, chronic kidney disease; AHF, acute heart failure; ACS, acute coronary syndrome; EF, ejection fraction; LVMI, left ventricular mass index; LVH, left ventricular hypertrophy; E/A, ratio of peak early to late diastolic filling velocity; IL-18, interleukin-18; BNP, B-type natriuretic peptide; AKI, acute kidney injury; RRT, renal replacement therapy. of urine interleukin 18 and the composite outcome of postdischarge RRT and/or 6-month mortality in patients with acute heart disorders. Patients with the highest quartile of urine IL-18 (>139.92 pg/mL) experienced RRT and/or 6-month mortality 6.7 times more frequently in comparison to patients with second and third quartile of urine IL-18 (HR 6.7, 95\% CI [2.8-16]; $P<0.0001$ ). There was no statistically significant difference $(P=0.38)$ between patients with second and third quartile of urine IL-18 (0.00-16.38 pg/mL and 16.39-139.91 pg/mL).

The ROC curve for plasma BNP produced an AUC of $0.76(P<0.001)$ with a sensitivity of $66.7 \%$ and specificity of $70.8 \%$ for the cutoff point of $881.6 \mathrm{pg} / \mathrm{mL}$ (Figure 1). Figure 3 shows Kaplan-Meier curves displaying the relationship between concentrations of plasma BNP and the composite outcome of RRT and/or 6-month mortality in patients with acute heart disorders. Patients with baseline plasma concentrations of $\mathrm{BNP}>663.4 \mathrm{pg} / \mathrm{mL}$ reached the postdischarge RRT and/or 6-month mortality 3.01 times more frequently than patients with baseline plasma concentrations of BNP $<663.4 \mathrm{pg} / \mathrm{mL}$ (HR 3.01, 95\% CI [1.25-7.3]; $P=0.014)$. BNP values were divided into two parts rather than quartiles because there was no significant difference between quartiles.

\section{Discussion}

In the present study, urine IL-18, plasma BNP, APACHE II score and left ventricular diastolic dysfunction predicted the risk of dialysis and/or 6-month mortality in patients hospitalized in ICUs for AHF and/or ACS. Patients with urine IL-18 concentrations $>139.92 \mathrm{pg} / \mathrm{mL}$ and plasma BNP values $>663.4 \mathrm{pg} / \mathrm{mL}$ were at significantly higher risk for postdischarge death and/or dialysis compared with patients with lower plasma BNP and urine IL-18 concentrations. Although of similar strength in univariate Cox analysis, the association of serum cystatin $\mathrm{C}$ and serum IL-18 with the postdischarged need for dialysis and/ or death was statistically insignificant after adjustment for clinical confounders in our multivariate Cox analysis.

IL-18 is a pro-inflammatory cytokine that is linked to accelerated atherosclerosis. Higher concentrations of serum IL-18 were detected in unstable atherosclerotic plaques in humans $(19,20)$. In the patients diagnosed with ACS, the serum IL-18 levels showed prognostic value for predicting all-cause mortality and noncardiovascular mortality (21). Although serum and urine IL-18 were both associated with adverse composite outcome of RRT and/or 6-month mortality in the present study, only urine IL-18 showed independent association in multivariate Cox analysis. Previous research confirmed that proximal tubule epithelial cells in the kidney express IL-18 only a few hours after renal injury. Therefore, increased levels of urine IL-18 are likely to be found in patients with acute tubular necrosis (22). The utility of urine IL-18 as a marker of adverse renal outcome and mortality was already verified in the population of critically ill patients (7). 
Table 2. Comparison of the baseline characteristic of patients with acute heart disorders according to the postdischarge requirement of RRT and/or 6-month mortality

\begin{tabular}{|c|c|c|c|}
\hline Variable & $\begin{array}{l}\text { Renal and/or overall } \\
\text { nonsurvivors }(n=25)\end{array}$ & $\begin{array}{l}\text { Renal and/or overall survivors } \\
\qquad(\mathrm{n}=95)\end{array}$ & $P$ \\
\hline BUN & $11.4(8.7-15)$ & $7.5(6.0-10.2)$ & $<0.001^{*}$ \\
\hline Serum creatinine & $117.0(93.0-148)$ & $82.5(72.0-105)$ & $<0.001^{*}$ \\
\hline APACHE II score & $15.5 \pm 4.6$ & $9.9 \pm 3.8$ & $<0.001^{*}$ \\
\hline $\mathrm{CCl}$ score & $8.7 \pm 1.6$ & $5.3 \pm 2.3$ & $<0.001 *$ \\
\hline CKD & $17(68.0 \%)$ & $23(24.2 \%)$ & $<0.001^{*}$ \\
\hline Diabetes mellitus & $13(52.0 \%)$ & $35(36.8 \%)$ & 0.17 \\
\hline Hypertension & 19 (76\%) & $68(71.6 \%)$ & 0.66 \\
\hline $\mathrm{EF}$ & $36.2 \pm 10.8$ & $41.5 \pm 10.2$ & $0.032 *$ \\
\hline$E F<35$ & $10(40.0 \%)$ & $22(23.2 \%)$ & \\
\hline EF 35-50 & $12(48.0 \%)$ & 49 (51.6\%) & 0.17 \\
\hline$E F>50$ & $3(12.0 \%)$ & $24(25.3 \%)$ & \\
\hline$E / A$ & $0.79 \pm 0.4$ & $0.91 \pm 0.3$ & 0.14 \\
\hline Diastolic dysfunction (abnormal relaxation) & $11(44.0 \%)$ & $12(12.8 \%)$ & \\
\hline Diastolic dysfunction (pseudo-normalization) & $9(36.0 \%)$ & 49 (52.1\%) & $0.002 *$ \\
\hline Diastolic dysfunction (restrictive filling) & $5(20.0 \%)$ & $33(35.1 \%)$ & \\
\hline Serum cystatin C & $1.8(1.3-2.7)$ & $1.2(0.9-1.6)$ & $<0.001^{*}$ \\
\hline Serum IL-18 & $258.30(209.00-484.10)$ & $71.48(26.37-192.40)$ & $0.001 *$ \\
\hline Urine IL-18 & $139.92(0.0-201.23)$ & $0.0(0.0-56.01)$ & $<0.001^{*}$ \\
\hline Plasma BNP & $1048.7(568.90-2424.40$ & $524.00(175.90-1089.30$ & $<0.001^{*}$ \\
\hline
\end{tabular}

Data are presented as number (percent) or mean \pm standard deviation, or median (interquartile range), * $P<0.05$.

RRT, renal replacement therapy; $n$, number; BUN, blood urea nitrogen; APACHE, Acute Physiology and Chronic Health Evaluation; CCI, Charlson comorbidity index; CKD, chronic kidney disease; EF, ejection fraction; E/A, ratio of peak early to late diastolic filling velocity; IL-18, interleukin-18; BNP, B-type natriuretic peptide.

Similarly to our results, this finding was mainly influenced by mortality, which was the predominant event in this composite outcome. In the patients admitted for acute hear failure, urine IL-18 was strongly associated with mortality, but it showed only modest ability to predict renal outcome (23). However, our results confirmed the ability of urine IL-18 not only to predict 6-month mortality but also need for postdischarge dialysis. Kaplan-Meier curves displayed a strong relationship between the highest concentrations of urine IL-18 and the composite outcome of dialysis and/or mortality in patients with acute heart disorders. Patients with the highest quartile of urine IL-18 (>139,92 $\mathrm{pg} / \mathrm{mL}$ ) were 6.7 times more likely to experience RRT and/or mortality in comparison with patients with second and third quartile of urine interleukin 18. Similarly to our results, heart surgery patients with the highest tertiles of peak urine IL-18 were linked to higher mortality risk compared with the patients with the lowest tertiles (24). Association between elevated levels of urine IL-18 with dialysis and mortality can be explained by the ability of this renal biomarker to identify kidney injury, and possible further influence in damaging other vital organs in the body (25). Severe AKI that require dialysis can be linked to long-term complications such as high mortality riks because of damaging distinct organs.

The BNP is a hormone produced by cardiomyocytes as a response to ventricular dysfunction and increased myocardial stress. The previous investigation confirmed the diagnostic and prognostic importance of BNP in patients with HF (26). However, a recent study showed the significant association of BNP with higher longterm mortality risk in patients diagnosed with ACS (27). In ACS patients, levels of BNP are likely increasing due to stiffening of left ventricular as a result of myocardial ischemia. In the setting of HF, there is a well-described connection between ventricular dilatation, high central venous pressure (CVP) and renal dysfunction. As a result of increased CVP and renal congestion, glomerular filtration and sodium excretion are decreasing, therefore BNP has a physiologically important role in cardiorenal axis (28). Nevertheless, the role of natriuretic peptides in predicting the maximum stage of AKI and the requirement of RRT was investigated only in critically ill patients admitted to intensive care unit for causes that excluded acute heart disorders (29). To our best knowledge, the present study was the first to evaluate the role of BNP in predicting the composite outcome of dialysis and/or death after hospitalization for acute heart disorders. KaplanMeier curves displayed a strong relationship between concentrations of plasma BNP and the composite outcome of mortality and/or dialysis. AHF and/or ACS patients with baseline concentrations of plasma BNP >663.4 pg/ $\mathrm{mL}$ reached the endpoint (postdischarge mortality and/ or RRT) 3 times more frequently than patients with baseline plasma concentrations of BNP $<663.4 \mathrm{pg} / \mathrm{mL}$. Prognostic value of BNP in predicting dialysis was already investigated in patients with CKD stage 4 and 5. BNP concentration $>140 \mathrm{ng} / \mathrm{L}$ predicted the requirement of 
Table 3. Cox proportional hazards regression analyses of prognostic factors for the postdischarge requirement of RRT and/or 6-month mortality in patients with acute heart disorders

\begin{tabular}{|c|c|c|c|}
\hline Parameter & B & $\mathrm{HR}(95 \% \mathrm{Cl})$ & $\boldsymbol{P}$ \\
\hline \multicolumn{4}{|c|}{ Univariate proportional hazard regression analysis } \\
\hline Age & 0.054 & $1.056(1.013-1.1)$ & $0.01 *$ \\
\hline $\mathrm{Hgb}$ & -0.01 & $0.987(0.97-1.004)$ & 0.23 \\
\hline BUN & 3.12 & $22.6(4.1-126.4)$ & $<0.0001^{*}$ \\
\hline Serum creatinine & 2.82 & $16.9(3,3-86,5)$ & $0.001 *$ \\
\hline eGFR & -0.03 & $0.97(0.95-0.99)$ & $<0.0001^{*}$ \\
\hline Albuminuria & 1.17 & $3.2(1.93-5.35)$ & $<0.0001^{*}$ \\
\hline Proteinuria & 2.23 & $9.3(3.99-21.8)$ & $<0.0001^{*}$ \\
\hline CRP & 1.76 & $5.8(2.58-13.0)$ & $<0.0001^{*}$ \\
\hline Uric acid & 3.98 & $53.2(4.4-640.0)$ & $0.002 *$ \\
\hline Troponin I & 0.11 & $1.11(0.72-1.7)$ & 0.623 \\
\hline Mean arterial pressure & -0.025 & $0.975(0.954-0.996)$ & $0.018^{*}$ \\
\hline Urine output & -1.17 & $0.181(0.08-0.422)$ & $<0.0001^{*}$ \\
\hline APACHE II score & 0.21 & $1.23(1.14-1.34)$ & $<0.0001^{*}$ \\
\hline $\mathrm{CCl}$ score & 0.553 & $1.74(1.42-2.13)$ & $<0.0001^{*}$ \\
\hline EF & -0.05 & $0.951(0.913-0.99)$ & $0.015^{*}$ \\
\hline LVMI & 0.012 & $1.012(1.0-1.02)$ & 0.05 \\
\hline Severe systolic dysfunction & 1.36 & $3.88(1.25-12.0)$ & $0.019 *$ \\
\hline Diastolic dysfunction (abnormal relaxation) & 1.07 & $0.34(0.15-0.77)$ & $0.009^{*}$ \\
\hline CKD & 1.54 & $0.21(0.091-0.499)$ & $<0.0001^{*}$ \\
\hline Diabetes mellitus & 0.59 & $1.8(0.8-4.0)$ & 0.148 \\
\hline Hypertension & 0.15 & $1.17(0.46-2.9)$ & 0.74 \\
\hline Anemia & 0.24 & $1.27(0.557-2.9)$ & 0.57 \\
\hline Serum cystatin C & 3.1 & $22.2(4.48-110.2)$ & $<0.0001^{*}$ \\
\hline Serum IL-18 & 1.73 & $5.7(2.2-14.6)$ & $<0.0001^{*}$ \\
\hline Urine IL-18 & 4.2 & $65.4(4.2-101.0)$ & $0.003^{*}$ \\
\hline Plasma BNP & 2.07 & $7.92(2.79-22.5)$ & $<0.0001^{*}$ \\
\hline AKI & 1.4 & $4.12(1.7-9.9)$ & $0.002 *$ \\
\hline \multicolumn{4}{|c|}{ Multivariate proportional hazard regression analysis } \\
\hline Urine IL-18 & 3.75 & $42.5(1.75-103.1)$ & $0.021 *$ \\
\hline Plasma BNP & 1.59 & $4.93(1.03-23.6)$ & $0.046^{*}$ \\
\hline APACHE II score & 0.187 & $1.2(1.07-1.36)$ & $0.002^{*}$ \\
\hline Diastolic dysfunction (abnormal relaxation) & 1.14 & $3.13(1.03-9.5)$ & $0.045^{*}$ \\
\hline
\end{tabular}

RRT, renal replacement therapy; HR, hazard ratio; $\mathrm{Cl}$, confidence interval; Hgb, hemoglobin; BUN, blood urea nitrogen; eGFR, estimated glomerular filtration rate; CRP, C-reactive protein; APACHE, Acute Physiology and Chronic Health Evaluation; CCl, Charlson comorbidity index; EF, ejection fraction; LVMI, left ventricular mass index; CKD, chronic kidney disease; IL-18, interleukin-18; BNP, B-type natriuretic peptide; AKI, acute kidney injury.

dialysis in a 1-year and 5-year period, but there was no significant association between BNP and death in this patient population (30). Different cutoff points of BNP in the present study and study of patients with CKD stages 4 and 5 can be explained with a rather high percentage of AHF (66.4\%) as an underlying factor for the hospital admission in our study. Patients with acute heart disorders in the present study had a history of any stage of CKD in approximately one-third of patients (35.9\%), but high prevalence of comorbidities such as LVH (77.1\%), systolic dysfunction (66.4\%) and diastolic dysfunction (72.5\%). It is already established that plasma concentrations of BNP are increased as a combined consequence of impaired renal clearance, fluid overload, as well as systolic and diastolic heart dysfunction (31). Diastolic dysfunction was also a predictor of RRT and/or death after hospitalization of patients with acute heart disorders in the present study. Previous studies confirmed the significance of diastolic dysfunction in predicting cardiovascular morbidity and mortality in the general population and population of patients treated with acute and chronic dialysis (32-34).

The present study confirmed that higher values of APACHE II score were independent predictors of RRT and/or 6-month mortality after hospital discharge of patients with acute heart disorders. The Acute Physiology and Chronic Health Evaluation is a prognosis scoring system that estimates the chance for mortality in ICUs. This scoring system is based on the evaluation of a large number of laboratory parameters, the clinical presentation of the patient as well as the presence of acute conditions and chronic comorbid diseases. Therefore, it was not surprising that we confirmed its prognostic value in the 


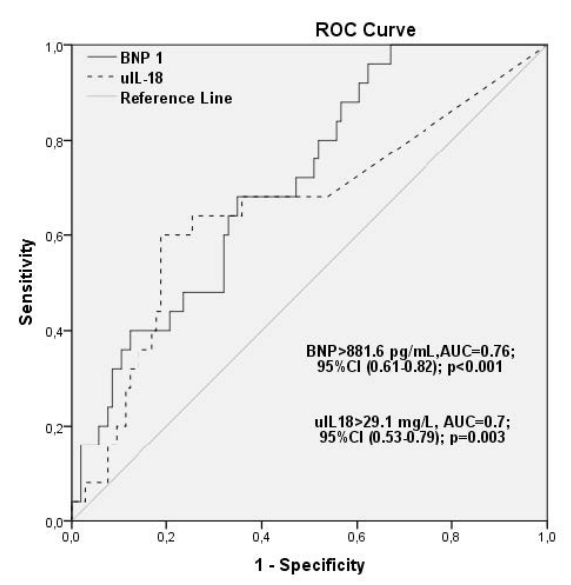

Figure 1. The ROC curve for ulL-18 and plasma BNP in the prediction of the postdischarge requirement of RRT and/or 6-month mortality in patients with acute heart disorders.

ROC, receiver operating characteristic; BNP, B-type natriuretic peptide; ulL-18, urine interleukin-18; AUC, area under curve; $\mathrm{Cl}$, confidence interval; RRT, renal replacement therapy.

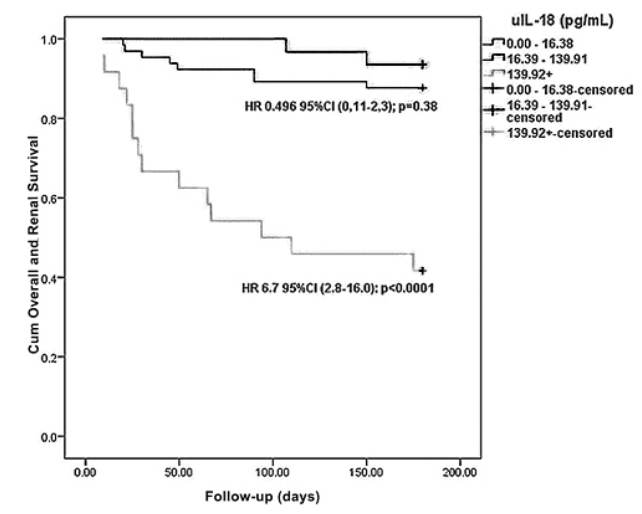

Figure 2. Kaplan-Meier curves for the composite outcome (the postdischarge requirement of RRT and/or 6-month mortality) in patients with acute heart disorders according to the different concentrations of ulL-18.

ulL-18, urine interleukin-18; $\mathrm{HR}$, hazard ratio; $\mathrm{Cl}$, confidence interval; RRT, renal replacement therapy.

present study of individuals hospitalized in ICUs for AHF and/or ACS. Electrolyte, mineral and hemodynamic disturbances are common in individuals with acute heart disorders, and the APACHE II score reflects the extent of these disorders in severe patients. Previously, the APACHE II scoring system confirmed an independent association with mortality in coronary ICU patients and ICU patients diagnosed with AKI $(10,35)$. However, in the present study, the APACHE II score predicted not only postdischarge mortality but also need for dialysis in patients with acute heart disorders. To the best of our knowledge, the ability of the APACHE II to predict RRT was evaluated only in the group of AKI patients so far. A recent study performed in China revealed that AKI patients with a high APACHE

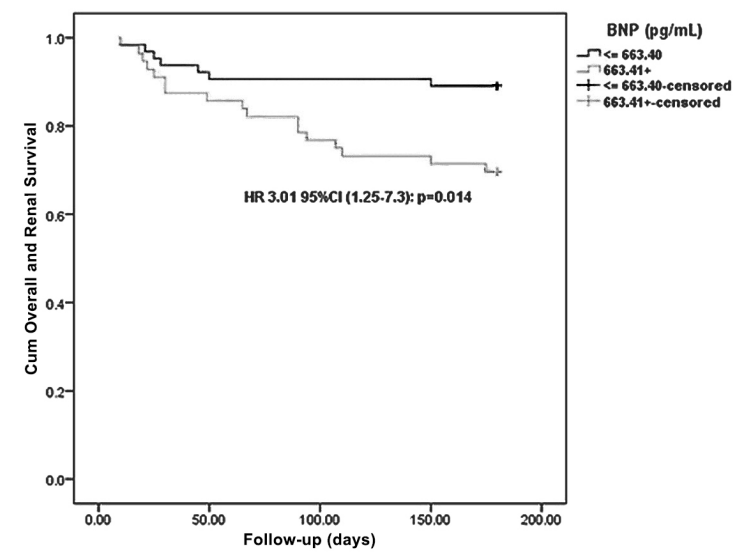

Figure 3. Kaplan-Meier curves for the composite outcome (the postdischarge requirement of RRT and/or 6-month mortality) in patients with acute heart disorders according to the different concentrations of plasma BNP.

BNP, B-type natriuretic peptide; HR, hazard ratio; $\mathrm{Cl}$, confidence interval; $\mathrm{RRT}$, renal replacement therapy.

II score are more prone to receive dialysis (36).

Conclusion

Urine IL-18, plasma BNP, APACHE II score and left ventricular diastolic dysfunction, at the time of hospital admission, provide valuable prognostic information for postdischarge dialysis risk and/or 6-month mortality in individuals with acute heart disorders.

Limitations of the study

The main restriction of the study was the fact that it was a single-center investigation that included relatively small number of patients. Furthermore, we analyzed selected, but not all potentially significant cardiorenal biomarkers. However, we monitored the prognostic value of biomarkers of renal injury and HF in the predicting postdischarge need for dialysis which has not been extensively studied in patients with acute heart disorders so far. Further studies on this subject are recommended.

\section{Acknowledgments}

This work was presented in the form of abstract at the $7^{\text {th }}$ Croatian Symposium on Renal Replacement Therapy with International Participation, Opatija, Croatia, October 11 $14,2018$.

\section{Authors' contribution}

AHM and DR created the study. VH, AHM, and ADN collected the data. AV analyzed the data. AHM wrote the paper. HČ revised the English version of the manuscript. AKĆ supervised the project. All authors accepted final version of manuscript for publication.

\section{Conflicts of interest}

The authors declared no competing interests. 


\section{Ethical considerations}

Ethical issues (including the fabrication of the data, plagiarism, and double publication) have been completely considered by the authors.

\section{Funding/Support}

None.

\section{References}

1. Adams KF Jr, Fonarow GC, Emerman CL, LeJemtel TH, Costanzo MR, Abraham WT, et al; ADHERE Scientific Advisory Committee and Investigators. Characteristics and outcomes of patients hospitalized for heart failure in the United States: rationale, design, and preliminary observations from the first 100,000 cases in the Acute Decompensated Heart Failure National Registry (ADHERE). Am Heart J. 2005;149:209-16. doi: 10.1016/j. ahj.2004.08.005.

2. AlFaleh HF, Alsuwaida AO, Ullah A, Hersi A, AlHabib KF, AlNemer $\mathrm{K}$, et al. The prognostic impact of in-hospital worsening of renal function in patients with acute coronary syndrome. Int J Cardiol. 2013;167:866-70. doi: 10.1016/j. ijcard.2012.01.097.

3. George LK, Koshy SKG, Molnar MZ, Thomas F, Lu JL, Kalantar-Zadeh $\mathrm{K}$, et al. Heart failure increases the risk of adverse renal outcomes in patients with normal kidney function. Circ Heart Fail. 2017;10:e003825. doi: 10.1161/ CIRCHEARTFAILURE.116.003825

4. AlFaleh HF, Alsuwaida AO, Ullah A, Hersi A, AlHabib KF, AlNemer K, et al. The prognostic impact of in-hospital worsening of renal function in patients with acute coronary syndrome. Int J Cardiol. 2013;167:866-70. doi: 10.1016/j. ijcard.2012.01.097.

5. Vandenberghe W, Gevaert S, Kellum JA, Bagshaw SM, Peperstraete H, Herck I, et al. Acute kidney injury in cardiorenal syndrome type 1 patients: a systematic review and meta-analysis. Cardiorenal Med. 2016;6:116-28. doi: $10.1159 / 000442300$

6. 6.Koyner JL, Garg AX, Coca SG, Sint K, Thiessen-Philbrook H, Patel UD, et al; TRIBE-AKI Consortium. Biomarkers predict progression of acute kidney injury after cardiac surgery. J Am Soc Nephrol. 2012;23:905-14. doi: 10.1681/ ASN.2011090907.

7. Siew ED, Ikizler TA, Gebretsadik T, Shintani A, Wickersham $\mathrm{N}$, Bossert F, et al. Elevated urinary IL-18 levels at the time of ICU admission predict adverse clinical outcomes. Clin J Am Soc Nephrol. 2010;5:1497-1505. doi: 10.2215/ CJN.09061209.

8. Hall IE, Yarlagadda SG, Coca SG, Wang Z, Doshi M, Devarajan P, et al. IL-18 and urinary NGAL predict dialysis and graft recovery after kidney transplantation. J Am Soc Nephrol. 2010;21:189-97. doi: 10.1681/ASN.2009030264.

9. Cao RY, Zheng H, Guo J, Redfearn DP. Prognostic value of plasma biomarkers in patients with acute coronary syndrome: a review of advances in the past decade. Biomark Med. 2016;10:525-35. doi: 10.2217/bmm-2015-0029.

10. Chen TH, Chang CH, Lin CY, Jenq CC, Hang MY, Tian $\mathrm{YC}$, et al. Acute kidney injury biomarkers for patients in a coronary care unit: a prospective cohort study. Plos One 2012;7:e32328. doi: 10.1371/journal.pone.0032328.

11. McMurray JJ, Adamopoulos S, Anker SD, Auricchio A, Böhm M, Dickstein K, et al; Task Force for the Diagnosis and Treatment of Acute and Chronic Heart Failure 2012 of the European Society of Cardiology; ESC Committee for Practice Guidelines. ESC guidelines for the diagnosis and treatment of acute and chronic heart failure 2012: The Task Force for the Diagnosis and Treatment of Acute and Chronic Heart Failure 2012 of the European Society of Cardiology. Developed in collaboration with the Heart Failure Association (HFA) of the ESC. Eur J Heart Fail. 2012;14:803-69. doi: 10.1093/eurjhf/hfs105.

12. Thygesen K, Alpert JS, Jaffe AS, Simoons ML, Chaitman BR, White HD; Writing Group on the Joint ESC/ACCF/AHA/ WHF Task Force for the Universal Definition of Myocardial Infarction; ESC Committee for Practice Guidelines (CPG). Third universal definition of myocardial infarction. Eur Heart J. 2012;33:2551-67. doi: 10.1093/eurheartj/ehs184.

13. Levey AS, Stevens LA, Schmid CH, Zhang YL, Castro AF 3rd, Feldman HI, et al; CKD-EPI (Chronic Kidney Disease Epidemiology Collaboration). A new equation to estimate glomerular filtration rate. Ann Intern Med. 2009;150:60412. doi: 10.7326/0003-4819-150-9-200905050-00006.

14. Quan H, Sundararajan V, Halfon P, Fong A, Burnand B, Luthi JC, et al. Coding algorithms for defining comorbidities in ICD-9-CM and ICD-10 administrative data. Med Care. 2005;43:1130-9.

15. Knaus WA, Draper EA, Wagner DP, Zimmerman JE. APACHE II: a severity of disease classification system. Crit Care Med. 1985;13:818-29.

16. Lang RM, Badano LP, Mor-Avi V, Afilalo J, Armstrong A, Ernande L, et al. Recommendations for cardiac chamber quantification by echocardiography in adults: an update from the American Society of Echocardiography and the European Association of Cardiovascular Imaging. J Am Soc Echocardiogr. 2015;28:1-39.e14. doi: 10.1016/j. echo.2014.10.003.

17. Nagueh SF, Appleton CP, Gillebert TC, Marino PN, Oh JK, Smiseth OA, et al. Recommendations for the evaluation of left ventricular diastolic function by echocardiography. J Am Soc Echocardiogr. 2009;22:107-33. doi: 10.1016/j. echo.2008.11.023

18. Mehta RL, Kellum JA, Shah SV, Molitoris BA, Ronco C, Warnock DG, et al. Acute Kidney Injury Network: report of an initiative to improve outcomes in acute kidney injury. Crit Care. 2007;11:R31. doi: 10.1186/cc5713.

19. Kurts C, Panzer U, Anders HJ, Rees AJ. The immune system and kidney disease: basic concepts and clinical implications. Nat Rev Immunol. 2013;13:738-53. doi: 10.1038/nri3523.

20. Hulthe J, McPheat W, Samnegård A, Tornvall P, Hamsten A, Eriksson P. Plasma interleukin (IL)-18 concentrations is elevated in patients with previous myocardial infarction and related to severity of coronary atherosclerosis independently of C-reactive protein and IL-6. Atherosclerosis. 2006;188:450-4. doi: 10.1016/j.atherosclerosis.2005.11.013.

21. Hartford M, Wiklund O, Hultén LM, Persson A, Karlsson T, Herlitz J, et al. Interleukin-18 as a predictor of future events in patients with acute coronary syndromes. Arterioscler Thromb Vasc Biol. 2010;30:2039-46. doi: 10.1161/ ATVBAHA.109.202697.

22. Parikh CR, Jani A, Melnikov VY, Faubel S, Edelstein CL. 
Urinary interleukin-18 is a marker of human acute tubular necrosis. Am J Kidney Dis. 2004;43:405-14.

23. Verbrugge FH, Dupont M, Shao Z, Shrestha K, Singh D, Finucan $\mathrm{M}$, et al. Novel urinary biomarkers in detecting acute kidney injury, persistent renal impairment, and allcause mortality following decongestive therapy in acute decompensated heart failure. J Card Fail. 2013;19:621-8. doi: 10.1016/j.cardfail.2013.07.004.

24. Coca SG, Garg AX, Thiessen-Philbrook H, Koyner JL, Patel UD, Krumholz HM, et al; TRIBE-AKI Consortium. Urinary biomarkers of AKI and mortality 3 years after cardiac surgery. J Am Soc Nephrol. 2014;25:1063-71. doi: 10.1681/ASN.2013070742.

25. Kelly KJ. Distant effects of experimental renal ischemia/ reperfusion injury. J Am Soc Nephrol. 2003;14:1549-58. doi: 10.1097/01.asn.0000064946.94590.46.

26. Palazzuoli A, Masson S, Ronco C, Maisel A. Clinical relevance of biomarkers in heart failure and cardiorenal syndrome: the role of natriuretic peptides and troponin. Heart Fail Rev. 2014;19:267-84. doi: 10.1007/s10741-0139391-x.

27. Scotti AV, Tura BR, Rocha RG, Albuquerque DC. Prognostic value of B-type natriuretic peptide in the mortality of patients with acute coronary syndrome. Arq Bras Cardiol. 2012;99:605-12. doi: 10.1590/s0066-782x2012005000050.

28. Ronco C, McCullough PA, Anker SD, Anand I, Aspromonte $\mathrm{N}$, Bagshaw SM, et al; Acute Dialysis Quality Initiative (ADQI) consensus group. Cardiorenal syndromes: an executive summary from the consensus conference of the Acute Dialysis Quality Initiative (ADQI). Contrib Nephrol. 2010;165:54-67. doi: 10.1159/000313745.

29. Haines R, Crichton S, Wilson J, Treacher D, Ostermann M. Cardiac biomarkers are associated with maximum stage of acute kidney injury in critically ill patients: a prospective analysis. Critical Care. 2017;21:88. doi: 10.1186/s13054017-1674-5.

30. Sundqvist S, Larson T, Cauliez B, Bauer F, Dumont A, Le Roy F, et al. Clinical value of natriuretic peptides in predicting time to dialysis in stage 4 and 5 chronic kidney disease patients. PLoS One. 2016;11:e0159914. doi: 10.1371/ journal.pone.0159914.

31. Weber M, Hamm C. Role of B-type natriuretic peptide (BNP) and NT-proBNP in clinical routine. Heart. 2006;92:843-9. doi: 10.1136/hrt.2005.071233.

32. Bella JN, Palmieri V, Roman MJ, Liu JE, Welty TK, Lee ET, et al. Mitral ratio of peak early to late diastolic filling velocity as a predictor of mortality in middle-aged and elderly adults: the Strong Heart Study. Circulation. 2002;105:192833. doi: 10.1161/01.CIR.0000015076.37047.D9.

33. Kim SJ, Han SH, Park JT, Kim JK, Oh HJ, Yoo DE, et al. Left atrial volume is an independent predictor of mortality in CAPD patients. Nephrol Dial Transplant. 2011;26:3732-9. DOI: $10.1093 / \mathrm{ndt} / \mathrm{gfr} 118$.

34. Han JH, Han JS, Kim EJ, Doh FM, Koo HM, Kim CH, et al. Diastolic dysfunction is an independent predictor of cardiovascular events in incident dialysis patients with preserved systolic function. PLoS One. 2015;10:e0118694. doi: 10.1371/journal.pone.0118694.

35. Cruz MG, Dantas JG, Levi TM, Rocha Mde S, de Souza SP, Boa-Sorte N, et al. Septic versus non-septic acute kidney injury in critically ill patients: characteristics and clinical outcomes. Rev Bras Ter Intensiva. 2014;26:384-91. doi: 10.5935/0103-507X.20140059.

36. Y Mao, ZH Qin. Risk factors of acute kidney injury and dialysis among patients attending intensive care units in China. Int J Clin Exp Med. 2017;10:12056-67.

Copyright (C) 2019 The Author(s); Published by Nickan Research Institute. This is an open-access article distributed under the terms of the Creative Commons Attribution License (http://creativecommons.org/licenses/by/4.0), which permits unrestricted use, distribution, and reproduction in any medium, provided the original work is properly cited. 